\title{
ICA Occlusion by an ACTH- secreting pituitary adenoma post-TSS and irradiation
}

\author{
Diala El-Zammar*, Ryojo Akagami
}

\begin{abstract}
Occlusion of intracranial arteries by a pituitary adenoma with ensuing infarction is a rare occurrence. In this case study, we show the instance of a pituitary macroadenoma and apoplexy causing mechanical obstruction of the internal carotid artery with consequent infarction following transphenoidal surgery (TSS) and radiation therapy in a patient with Cushing's disease. We report a 44-year-old woman presented with amenorrhea and headaches. Necessary investigations, resection by TSS, and microscopic examination revealed an adenocorticotropin (ACTH)-secreting pituitary macroadenoma. The pituitary tumour recurred in subsequent years, resulting in the development of Cushing's disease and syndrome. Despite two more transphenoidal surgeries, radiotherapy, and medical suppressive therapy, the pituitary adenoma continued to enlarge, and the hypercortisolemia and Cushingoid symptoms persisted. A craniotomy was arranged as the next step in the treatment strategy. Only hours prior to the scheduled surgery, the patient developed left-sided hemiplegia, was diagnosed with acute occlusion of the right ICA and underwent an emergency bifrontal craniotomy with evacuation of the tumour and decompression. Pathological examination revealed evidence of apoplexy in the ACTH-secreting pituitary adenoma. This case demonstrates the vast scope of complications that can arise from pituitary adenomas despite combination therapy and forewarns clinicians to be prepared to manage these infrequent but conceivable occurrences.
\end{abstract}

KEYWORDS: Pituitary adenoma, Cushing's disease, pituitary apoplexy

\section{INTRODUCTION}

Adenocorticotropic hormone (ACTH)-secreting pituitary macroadenomas causing Cushing's disease is a rarity with an incidence of 0.7 to 2.4 cases per million inhabitants annually (1-3). Cushing's disease (CD) is a debilitating endocrinopathy that, for the clinician, is a challenge to diagnose and treat. The current treatment of choice for CD is transsphenoidal pituitary surgery (TSS), which is associated with long-term remission rates of $64-93 \%$. Lower range success rates are found

\footnotetext{
${ }^{*}$ To whom correspondence should be addressed:

Diala El-Zammar

University of British Columbia, Medical Undergraduate Program Tel. (778) 990-2341

Email: dinicola@interchange.ubc.ca
}

in patients with pituitary macroadenomas as compared to those with microadenomas (4-13). Current published literature has established that the mortality rate of TSS is less than $1 \%$, and morbidity is approximately $1.8 \%(1,5,12,14,15)$. A multiple modality approach, including surgery, radiotherapy, radiosurgery, and adrenalectomy, for the management of CD due to ACTH-secreting macroadenomas has also been shown to be effective (1). Despite the comprehensiveness of this therapeutic strategy, disease recurrence and persistence rates are still higher for macroadenomas than microadenomas; this is likely due to the invasive nature of macroadenomas (1). 

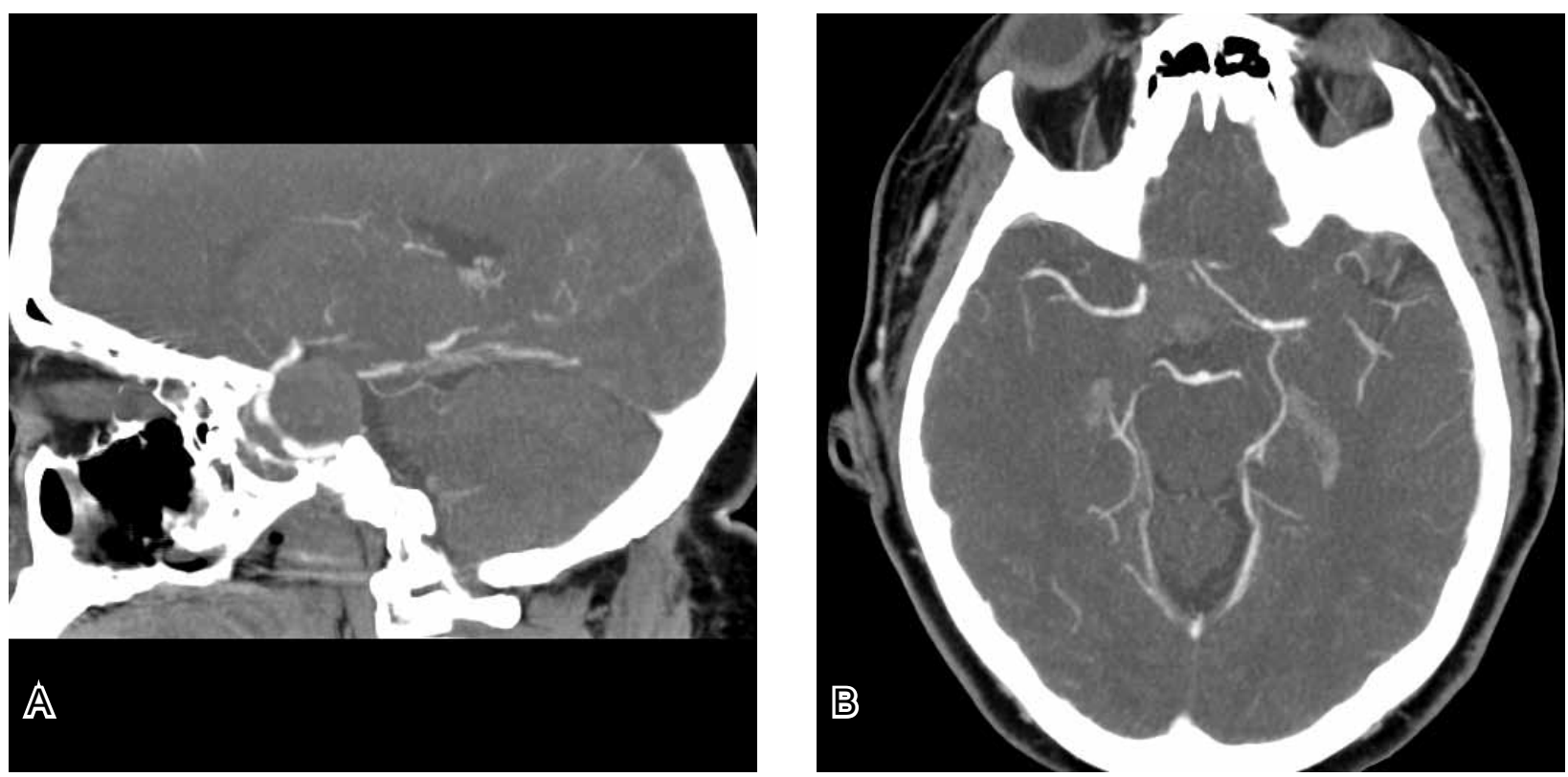

Figure 1: Pre-operative contrast-enhanced CT head showing a patent right carotid artery. CT scan also shows a well-circumscribed pituitary tumour measuring $3.3 \times 4.3 \times 3.9 \mathrm{~cm}$ with suprasellar extensions and marked elevation of the chiasmatic tissue. The arterial phase imaging demonstrates the right internal carotid artery to have a mildly redundant loop situated at the junction of its precavernous and cavernous segments due to mass effect upon the vessel by the tumour. The radiologist attributed the reduced calibre of the right ICA to possible stenosis. On the left, the ICA is not found to be as significantly displaced as on the right. (a) Sagittal view. (b) Axial view.

Complications can arise from pituitary adenomas as a direct result of the tumour itself or as a consequence of the treatment. Functional pituitary adenomas will be symptomatic in accordance with the type and quantity of the hormone they elaborate (16). For example, a prolactin (PRL)-secreting adenoma may present with infertility, galactorrhea, amenorrhea and decreased libido, while an ACTHreleasing adenoma involves weight gain, hypertension, diabetes, excessive hair growth, abdominal striae, and lipodystrophy of face and back. Likewise, a growth hormone (GH)-secreting tumour may present with acromegaly and gigantism, in contrast to a thyroid-stimulating hormone (TSH)-producing adenoma which causes tachycardia, palpitations, weight loss and heat intolerance (16).

Functional pituitary adenomas can secrete Although some functional pituitary tumours grow large enough to compress adjacent structures causing neurological symptoms and compromise of normal pituitary function, functional adenomas are less likely than non-functional tumours to do so (17). In rare cases, these tumours may spontaneously hemorrhage or become infarcted (18), a condition known as pituitary apoplexy. Some uncommon postoperative complications include infection, cerebrospinal leakage, vascular injury, double vision, visual loss, and pituitary deficiency (17). Two very rare post-TSS complications have been reported; one of these cases involved a false aneurysm of the cavernous carotid artery, and the other, a carotid cavernous fistula (19). Although there have been rare reports in the literature of pituitary apoplexy and cavernous carotid artery involvement in patients with a pituitary adenoma, there have been no cases reported of pre-operative intracranial artery infarct due to acute compression by a functional pituitary adenoma in a patient with clinical Cushing's disease.

\section{CASE REPORT}

A 44-year-old female of Jamaican ancestry presented with amenorrhea and headaches. She was diagnosed with a pituitary macroadenoma in 1998 and subsequently underwent three transphenoidal pituitary resections in 1998,2002 , and 2004. The patient's condition was complicated by Cushing's disease as evidenced by high cortisol levels and Cushingoid features of central obesity, hirsutism, striae, and thinning of the skin. These symptoms were managed by Ketoconazole for a few years. Her cortisol levels, however, continued to increase and the tumour had, as shown on follow-up scans, enlarged in size despite adjuvant radiotherapy treatment in 2005. A craniotomy and orbital osteotomy were arranged as the next course of action. While awaiting surgery, the patient developed some ptosis of her right eye. This, as well as 
a three-week history of decreased visual acuity and visual field deficits accompanied by headaches, led her to present herself to the emergency department at Vancouver General Hospital in February, 2007. On examination, she was found to have new right third nerve palsy while scans revealed no obvious hemorrhage or apoplexy within the tumour (Fig. 1). The patient was kept in hospital and surgery was scheduled. On the morning of the scheduled surgery day the patient experienced increasing headaches. Shortly after the neurosurgeon had examined the patient on rounds, she developed drowsiness, disorientation with Glascow Coma Scale (GCS) of 9 , and acute left-sided hemiparesis. The GCS is a score between 3 and 15 that provides an objective assessment of a person's state of consciousness, based on their best eye, verbal, and motor responses to stimuli. A GCS score of 8 or less is indicative of severe brain injury; a score of 9-12 is moderate, and one greater than 13 constitutes minor brain injury (17). Urgent evaluation and CT scan revealed an occlusion of the right carotid artery in the cavernous segment (Fig. 2), which had been patent and flowing on a head CT performed upon admission three days earlier (Fig. 1). There was no evidence of any obvious apoplexy or increase in size of tumour depicted on this pre-operative scan (Fig. 2). Acute occlusion of the right ICA was diagnosed and an emergent bifrontal craniotomy with evacuation of the tumour was performed.

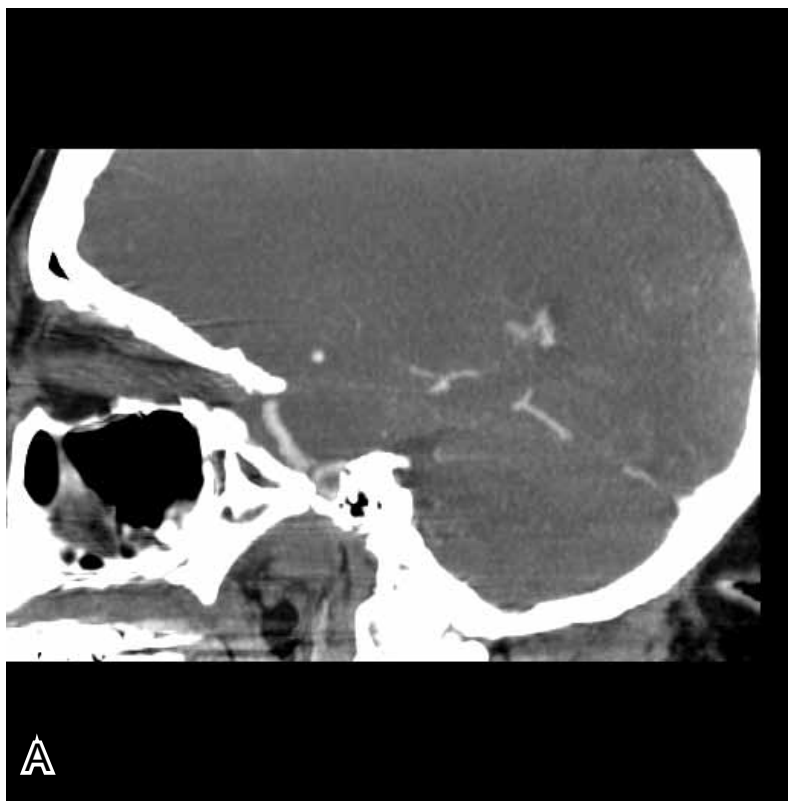

Microscopic examination of the pituitary adenoma displayed areas of recent hemorrhage and tumour necrosis, as well as increased nuclear pleomorphism. There was reported fibrinoid necrosis and hyaline degeneration, which are believed to be induced by irradiation. The neuropathologist concluded that the tumour was an ACTH-secreting pituitary adenoma displaying an unusual profile of immunoreactivity for Melan A.

Intra-operatively, a post decompression cerebral angiogram showed that the right ICA was patent (Fig. 3). Non-contrast CT head, done one day postoperatively, demonstrated near total right MCA and ACA territory infarction with sparing of the posterior right temporal territory (Fig. 4). There was also evidence of right cerebral edema, with near total effacement of the right lateral ventricle. Although a mild leftward shift of the anterior midline structures was observed, no transtentorial herniation was seen. Her postoperative course was also complicated by diabetes insipidus, which was treated with DDAVP.

A non-contract CT scan performed eight months later showed reduced mass effect and relief of the previous compression of the right lateral ventricle (Fig. 5). Extensive right ACA and MCA infarction with sparing of the posterior right temporal territory persisted. The CT scan confirmed no midline shift, hydrocephalus, or intracranial hemorrhage. It is noteworthy to mention that MRI investigations

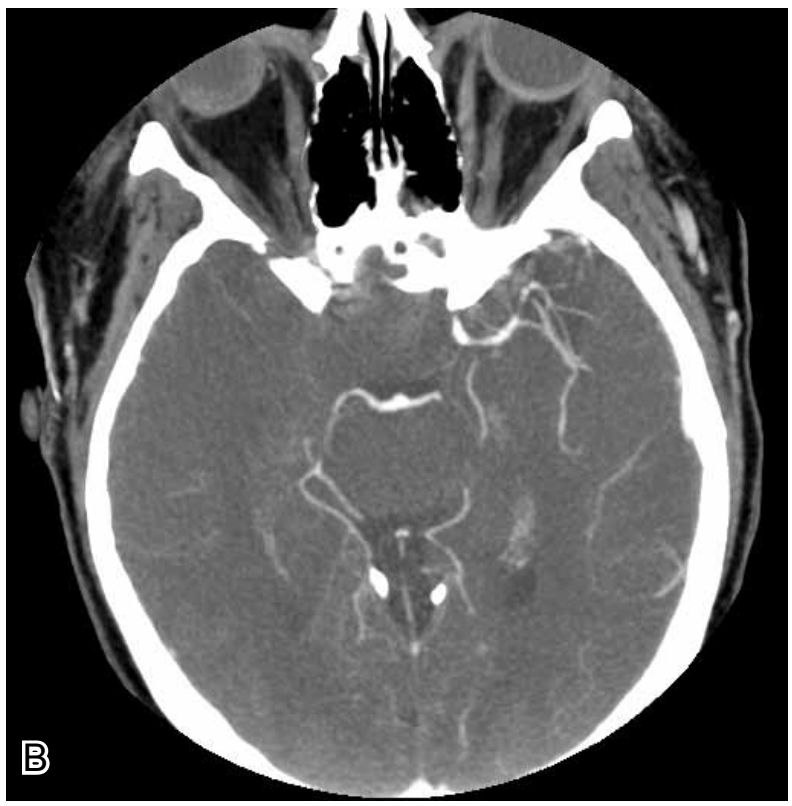

Figure 2: Pre-operative contrast-enhanced CT head on the day of the surgery showing an occluded right carotid artery. The right ICA is severely attenuated and compressed against the right anterior clinoid process by the pituitary mass. A very small right anterior communicating artery is noted with no significant posterior communicating artery seen bilaterally. (a) Sagittal view. (b) Axial view. 


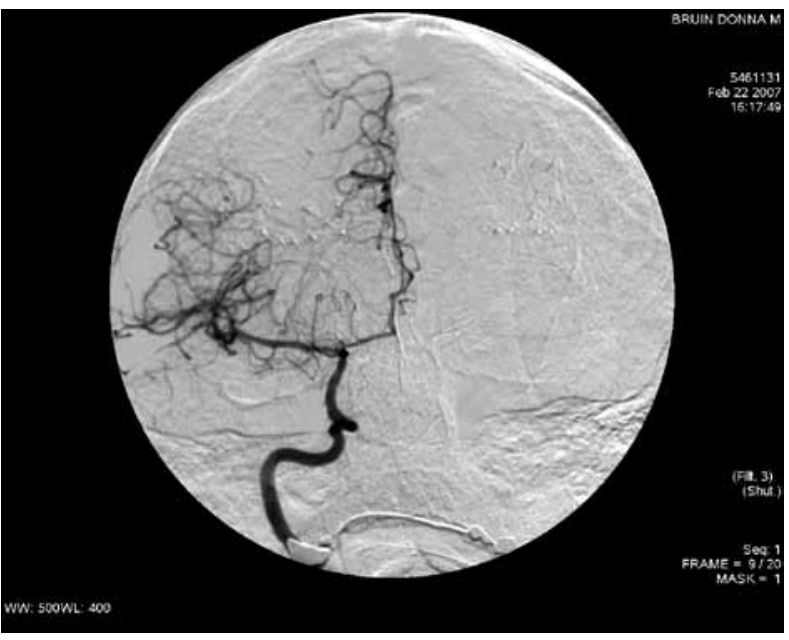

Figure 3: Intra-operative anteroposterior angiogram showing a patent right carotid artery

could not be performed due to the patient's severe claustrophobia.

Physical examination six months post-operatively reveal that the patient has improvement in her left leg strength, while her arm remains non functional; decreased sensation of her left side and left-sided neglect; no useful vision in her right eye; and a temporal field defect in the only seeing left eye (with the loss of vision in the right eye, it is difficult to conclude if she has a bitemporal defect or a

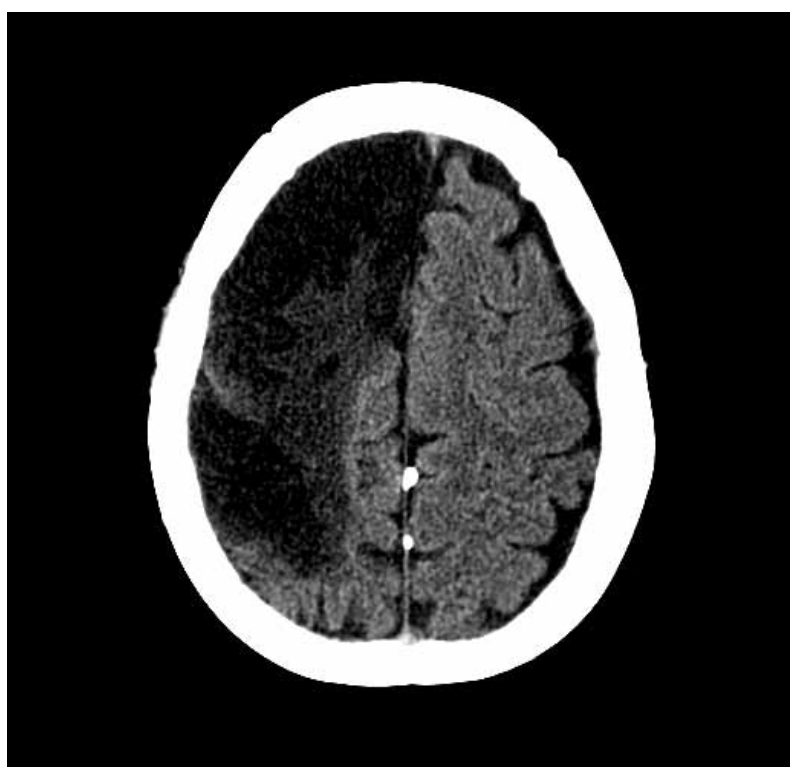

Figure 5: Eight months post-operative non-contrast CT head showing persistent extensive right ACA and MCA infarction with sparing of the posterior right temporal territory. CT scan also demonstrates reduced mass effect and relief of the previous compression of the right lateral ventricle and confirms no midline shift, hydrocephalus, or intracranial hemorrhage.

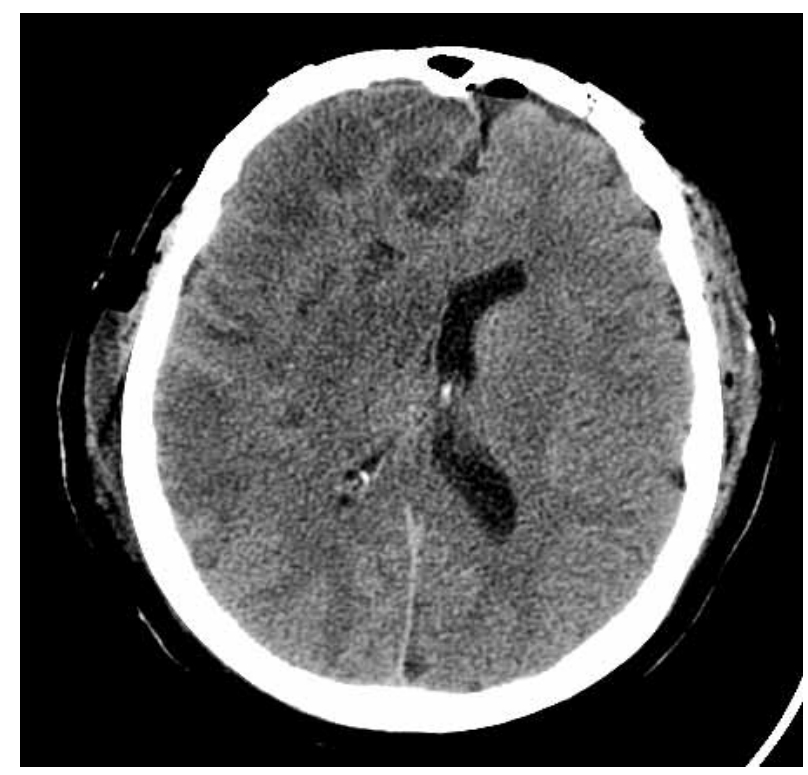

Figure 4: One day post-operative CT head showing near total right MCA and ACA territory infarction.

homonomous left field defect). Furthermore, some cognitive deficits, especially with maintaining attention, were noted in follow-up in the first year following the infarct. A more recent assessment by a psychiatrist, however, nearly three years after the stroke, shows significant improvement in cognitive function. The patient is orientated, pleasant, cooperative, able to converse in a normal manner with no overt cognitive deficits, and demonstrated fair insight and attention during the exam. She currently lives at home with assistance and her Cushing's disease remains in remission to date.

\section{DISCUSSION}

Despite the evidence showcasing the safety and effectiveness of transphenoidal surgery (TSS) as the primary treatment for Cushing's disease $(C D)(1,8,14)$, the pituitary macroadenoma recurred three times in this patient. In a multicentre study by the European Cushing's Disease Survey Group involving 668 patients from 25 institutions over a span of 15 years, the researchers noted a recurrence of Cushing's disease in $12.7 \%$ of patients after TSS. The tumour recurred after a mean remission period of 39.3 months (8). Moreover, Benveniste et al. (2005) have shown that repeated TSS is an effective treatment for recurrent or residual mass and has acceptable rates of morbidity and mortality (20). A study that followed 117 Cushing's disease patients for six years found that the remission rate of $85.4 \%$ after the first TSS decreased to 
$28.6 \%$ after the second TSS (21). Consequently, we may infer that the remission rate is anticipated to be even lower in our patient after a third TSS and that, perhaps TSS may not be the appropriate first choice of treatment in a patient whose first TSS was not curative. Due to the rarity of Cushing's disease, consensus has not been established as to the best first choice of treatment for recurrent or residual pituitary adenomas; thus, further investigation is warranted.

For patients with $C D$, alternative or adjuvant treatment options to TSS have been proposed in the literature, including bilaterial adrenalectomy $(22,23)$, medical therapy with adrenostatic drugs (24), radiotherapy (25), and radiosurgery (26). After the second TSS, adjuvant radiotherapy and medical adrenalectomy with Ketoconazole were administered to provide a combined therapeutic regime to our patient. The pituitary tumour was refractory despite this comprehensive treatment approach.

The unique features of this case are that an ACTHsecreting tumour grew to such a large extent that it caused compression of the internal carotid artery (ICA), resulting in cerebral infarction with some pituitary apoplexy. Review of the literature has enabled the generation of several potential explanations for this occurrence. This patient's pituitary adenoma is one of the $12.7 \%$ of refractory tumours that recur post-TSS (8). This tumour displayed this refractoriness to treatment since the first TSS and re-grew larger and faster subsequent to each TSS (Figs. 1-2). The tumour extended to the distribution of the cavernous sinus and encased the ICA. Although not obviously radiologically, both intraoperatively and pathologically there were some areas of recent pituitary apoplexy which likely resulted in increased pressure on the carotid artery.

A second explanation worth consideration is that the external beam radiation to the pituitary gland induced the development of vasculopathy in the ICA, which is in close proximity to the pituitary gland, and thus is contained in the radiation field. Reports of radiation-induced vasculopathy date as far back as the 1960s $(27,28)$. Since then, several other cases have surfaced in the literature. In 1993, Marriott et al. documented a case of delayed and focal post-irradiation intracranial vasculopathy resulting in intracranial stenosis. More recently, Penagaricano et al. (2004) make reference to a "syndrome of accelerated cerebral vasculopathy after cerebral radiation therapy" (29). Although conventional instruction in radiation oncology recognizes radiation injury to small vessels and capillaries, damage to large arteries is deemed uncommon.
Studies have documented carotid artery radiation injuries following external cervical irradiation where $25 \%$ of patients had abnormal phonoangiograms (30). Furthermore, Penagaricano et al. (2004) make the argument that radiation-induced vasculopathy in large arteries, though occuring some time after small vessel injury, may have a greater prevalence than currently presumed (29). The authors also present a case of anterior cerebral artery infarct resulting in a subacute stroke eighteen years following whole brain radiotherapy in a patient with no atherosclerotic risk factors (29). Similarly, Mizokami et al. (1996) report a case of Cushing's disease where the intracranial region exposed to repeated radiotherapy showed more prominent atherosclerosis on angiography compared to the unexposed areas. The pathophysiology is thought to involve large vessel pathology, such as intimal proliferation with or without atheromatosis, thrombosis, and occasional rupture, from targeted radiation at endothelial cells (29).

While the vascular disease that led to the ICA stroke may have been caused by radiotherapy, it may alternately have been the effect of chronic hypercortisolemia. Some studies have found evidence that high blood cortisol levels may be an independent risk factor for atherosclerosis. In one study, a correlation between blood cortisol levels and coronary atherosclerosis was noted, with the most significant association found between plasma cortisol and cholesterol (31). In yet another report, a relationship was identified between salivary cortisol and atherosclerosis of the carotid arteries (32). A review of the current literature (to be published in the journal Current Vascular Pharmacology in 2010) has attempted to elucidate the mechanism by which ACTH and cortisol contribute to atherosclerosis (33). Proposed mechanisms by which these hormones may induce atherogenesis include modulation of vascular endothelial function, recruitment of circulating monocytes to the artery wall and their differentiation into macrophages foam cells, and control of the expression of pro- and anti-inflammatory interleukins. The pathological changes caused by ACTH and cortisol that may lead to stroke include modulating platelet aggregation and thrombus formation (33). Moreover, the case report being presented here provides support to Mizokami et al.'s (1996) proposal that hypercortisolemia may also indirectly contribute to cerebrovascular accidents in patients with Cushing's disease as it accelerates the development of atherosclerotic risk factors such as hypertension, diabetes, dyslipidemia and central obesity (34), which are clinical mani- 
festations characteristic of Cushing's disease (17). The patient in this case was also diagnosed with hypertension and diabetes.

Finally, in our case, the etiology of the ICA stroke is most likely multifactorial - a consequence of radiation, hypercortisolemia, a refractory tumour type, and/ or the patient's atherosclerosis risk factors, which include diabetes and hypertension. Conclusion

This case suggests that pituitary adenomas of the refractory type, hypercortisolemia and/ or pituitary irradiation may be contributors to cerebral infarction in patients with Cushing's disease. It is thus of relevance to the clinician to ensure early diagnosis, close surveillance, and prompt treatment in an effort to prevent cerebrovascular complications in these patients. Also pertinent to the practitioner is the fact that repeated TSS, as was the case in this patient, may not be beneficial; in fact, the radiation may have contributed in part to her ischemic event. Cerebral angiography may be of worthy consideration in patients with refractory pituitary adenomas and atherosclerotic risk factors, especially if they have also received radiotherapy, or if they exhibit focal neurological signs and symptoms. In light of the rarity of Cushing's disease and the limited evidence-based research on this topic, it falls on the clinician to make individualized treatment decisions, taking patient and treatment factors into account, as well as considering the experience and hardships encountered by fellow colleagues in the management of this condition.

\section{REFERENCES}

1. De Tommasi C, Vance ML, Okonkwo DO, Diallo A, Laws ER Jr. Surgical management of adrenocorticotropic hormone-secreting macroadenomas: outcome and challenges in patients with Cushing's disease or Nelson's syndrome. J Neurosurg. 2005;103(5):825-30.

2. Ambrosi B, Faglia G, and Multicenter Pituitary Tumor Study Group, Lombardia Region. Pituitary Adenoma: new trends in basic and clinical research. Epidemiology of pituitary tumors. In: Faglia G, Beck-Pecoz P, Ambrosi B, Travaglini P, Sada A, eds. 1991; Amsterdam: Excerpts Medica, pp. 159168.

3. Etxabe J, Vazquez JA. Morbidity and mortality in Cushing's disease: an epidemiological approach. Clin Endocrinol (Oxf.). 1994;40: 479-484.

4. Esposito F, Dusick JR, Cohan P, Moftakhar P, McArthur D, Wang $C$ et al. Early morning cortisol levels as a predictor of remission after transsphenoidal surgery for Cushing's disease. J Clin Endocrinol Metab. 2006;91:7-13.

5. Laws ER, Reitmeyer M, Thapar K, Vance ML. Cushing's disease resulting from pituitary corticotrophic microadenoma. Treatment results from transsphenoidal microsurgery and gamma knife radiosurgery. Neurochirurgie. 2002;48:294-9.

6. EH., Oldfeld. Cushing's disease. J Neurosurg. 2003;98:94851.

7. Chen JC, Amar AP, Choi S, Singer P, Couldwell WT, Weiss $\mathrm{MH}$. Transsphenoidal microsurgical treatment of Cushing disease: postoperative assessment of surgical efficacy by application of an overnight low-dose dexamethasone suppression test. J Neurosurg. 2003;98:967-73.

8. Bochicchio D, Losa M, Buchfelder M. Factors influencing the immediate and late outcome of Cushing's disease treated by transsphenoidal surgery: a retrospective study by the European Cushing's Disease Survey Group. J Clin Endocrinol Metab. 1995;80(11):3114-20.

9. Reitmeyer M, Vance ML, Laws Jr ER. The neurosurgical management of Cushing's disease. Mol Cell Endocrinol. 2002;197:73-9.

10. Basis of persistent and recurrent Cushing's disease: an analysis of findings at repeated pituitary surgery. Dickerman RD, Oldfield EH. 2002, J Neurosurg, pp. 97: 1343-9.

11. Estrada J, Garcia-Uria J, Lamas C, Alfaro J, Lucas T, Diez $S$, et al. The complete normalization of the adrenocortical function as the criterion of cure after transsphenoidal surgery for Cushing's disease. J Clin Endocrinol Metab. 2001;86:5695-9.

12. Hammer GD, Tyrrell JB, Lamborn KR, Applebury CB, Hannegan ET, Bell S, et al. Transsphenoidal microsurgery for Cushing's disease: initial outcome and long-term results. J Clin Endocrinol Metab. 2004;89:6348-57.

13. Cannavo S, Almoto B, Dall'Asta C, Corsello S, Lovicu RM, De Menis $\mathrm{E}$, et al. Long-term results of treatment in patients with $\mathrm{ACTH}$-secreting pituitary macroadenomas. Eur J Endocrinol. 2003;149:195-200.

14. Kelly DF. Transsphenoidal surgery for Cushing's disease: a review of success rates, remission predictors, management of failed surgery, and Nelson's Syndrome. Neurosurg Focus. 2007;23(3):E5.

15. Semple PL, Laws Jr ER. Complications in a contemporary series of patients who underwent transsphenoidal surgery for Cushing's disease. J Neurosurg. 1999;91:175-9.

16. Gsponer J, De Tribolet N, Déruaz JP, et al. Diagnosis, treatment, and outcome of pituitary tumors and other abnormal intrasellar masses.Retrospective analysis of 353 patients. Medicine (Baltimore). 1999;78(4):236-69.

17. Khan AN, Turnbull I, Rudralingam V, Alonso A, James A, Munusamy $S$ et al. Pituitary Adenoma. Last updated Mar.12, 2009. Retrieved on Jul. 12, 2009, Medscape, pp. $<$ http://emedicine.medscape.com/article/343207-overview>.

18. Kim JP, Park BJ, Kim SB, Lim YJ. Pituitary Apoplexy due to Pituitary Adenoma Infarction. J Korean Neurosurg Soc. 
2008;43(5):246-9.

19. Kachhara R, Menon G, Bhattacharya RN, et al. False aneurysm of cavernous carotid artery and carotid cavernous fistula: complications following transsphenoidal surgery. Neurol India. 2003;51(1):81-3.

20. Benveniste RJ, King WA, Walsh J, Lee JS, Delman BN, Post KD. Repeated transsphenoidal surgery to treat recurrent or residual pituitary adenoma. J Neurosurg. 2005;102 (6):1004-12.

21. Rollin G, Ferreira NP, Czepielewski MA. Prospective evaluation of transsphenoidal pituitary surgery in 108 patients with Cushing's disease. Arg Bras Endocrinol Metabol. 2007;51 (8):1355-61.

22. Welbourn RB. Survival and causes of death after adrenalectomy for Cushing's disease. Surgery. 1985;97:16-20.

23. Lindholm J. Endocrine function in patients with Cushing's disease before and after treatment. Clin Endocrinol (Oxf). 1992;36:151-159.

24. Miller JW, Crapo L. The medical treatment of Cushing's syndrome. Endocr Rev. 1993. 14: 443-458.

25. Littley MD, Shalet SM, Beardwell CG, Ahmed SR, Sutton ML. Long-term follow-up of low-dose external pituitary irradiation for Cushing's disease. Clin Endocrinol (Oxf). 1990;33:445-455.

26. Degerblad M, Rahn T, Bergstrand G, Thoren M. Longterm results of stereotactic radiosurgery to the pituitary gland in Cushing's disease. Acta Endocrinol (Copenh). 1986;112:310-314.

27. Darmony WR, Thomas LM, Gurdjian ES. Postirradiation Vascular Insufficiency Syndrome. Neurology. 1967;17:1190-92.

28. Lee KF, Hodes PJ. Intracranial Ischemic Lesions. Rdiol Clin North Am. 1967:5:353-60.

29. Penagaricano JA, Linskey ME, Ratanatharathorn V. Accelerated cerebral vasculopathy after radiation therapy to the brain. Neurology India. 2004;52(4):482-486.

30. Elderding S, Fernandez R, Grotta J, Lindberg R, Causay LC, McMurtrey M. Carotid Artery Disease Following Exter- nal Cervical Irradiation. Ann Surg. 1991;194:609-15

31. Troxler RG, Sprague EA, Albanese RA, Fuchs R, Thompson AJ. The association of elevated plasma cortisol and early atherosclerosis as demonstrated by coronary angiography. Atherosclerosis. 1967;26(2):151-62.

32. Salivary cortisol is related to atherosclerosis of carotid arteries. Dekker MJ, Koper JW, van Aken MO, Pols HA, Hofman $\mathrm{A}$, de Jong $\mathrm{FH}$, et al. J Clin Endocrinol Metab. 2008;93(10):3741-7.

33. Fanditis P. The role of the Stress-Related Anti-Inflammatory Hormones ACTH and Cortisol in Atherosclerosis. Curr Vasc Pharmacol. 2010; "In Press".

34. Mizokami T, Okamura K, Sato K, Kuroda T, Sadoshima S, Fujishima M. Risk factors for brain infarction in patients with Cushing's disease. Case reports. Angiology. 1996;47(10):1011-7.

35. Erfurth EM, Hagmar L. Cerebrovascular disease in patients with pituitary tumors. Trends Endocrinol Metab. 2005;16(7):334-342.

36. Atkinson AB, Kennedy A, Wiggam MI, McCance DR, Sheridan $B$. Long-term remission rates after pituitary surgery for Cushing's disease: the need for long-term surveillance. Clin Endocrinol (Oxf). 2005;63(5):549-59.

37. Aghi MK. Management of recurrent and refractory Cushing disease. Nat Clin Pract Endocrinol Metab. 2008;4(10):5608.

38. Bademci G. Pitfalls in the management of Cushing's disease. J Clin Neurosci. 2007;14(5):401-8.

39. Yang SH, Lee KS, Lee KY, Lee SW, Hong YK. Pituitary apoplexy producing internal carotid artery compression: a case report. J Korean Med Sci. 2008;23(6):1113-7.

40. Dogan S, Kocaeli H, Abas F, Korfali E. Pituitary apoplexy as a cause of internal carotid artery occlusion. J Clin Neurosci. 2008;15(4):480-3.

41. Marriott E, Schneck MJ. Post-Radiation-Induced Symptomatic Intracranial Stenosis. Semin Cerebrovascular Dis Stroke. 2005;5(2):155-157.

Diala El-Zammar (MD (2011), BSc) is currently in medical school at the University of British Columbia (UBC). She also completed her BSc in Integrated Sciences with concentrations in Biochemistry and Medical Genetics, and a minor in English Language at UBC.

Ryojo Akagami (MD, FRCSC, BSc, MHSc) is a Neurosurgeon specializing in Skull Base surgery at the Vancouver General Hospital in British Columbia. He is the program director for the Neurosurgery residency at UBC and a Clinical Assistant professor in the Department of Surgery at UBC. 